\title{
Molecular Characterization of Isolated Multidrug- Resistant Bacteria from Tertiary Care Hospitals of Ahmedabad: A Comparison Study Between Previous to COVID-19 and Current Scenario
}

\author{
Anurag D. Zaveri ${ }^{1 *}(\mathbb{D})$, Dilip N. Zaveri ${ }^{(D)}$ and Lakshmi Bhaskaran ${ }^{1}(\mathbb{D}$ \\ ${ }^{1}$ Department of Microbiology and Biotechnology, KSV University, Gandhinagar, Gujarat, India. \\ ${ }^{2}$ Biocare Research India Pvt. Ltd., Ahmedabad, Gujarat, India.
}

\begin{abstract}
Hospital Acquired Infections (HAIs) are a significant concern for healthcare setups, as it increases the overall cost of treatment, patients stay in hospitals, making them susceptible to secondary and tertiary infections and, sometimes, mortality ${ }^{1}$. To prevent or control HAls, evaluating the organisms isolated from the critically maintained areas is considered of epitome importance and everlasting practice in the healthcare industry. Identifying such organisms and screening them for antibiotic resistance is mandatory, but it also helps professionals understand colonization trends. Sensitive areas of healthcare setups were screened monthly from years 2017 to 2020. A total of 4400 samples of hospital hygiene, e.g., intravenous drip stands, ventilator surface, anesthetist's trolley, patient's bed, instrument trolley, etcetera, were collected. Isolated organisms were cultured and screened using the CLSI technique. E. coli, Pseudomonas spp., and Klebsiella spp. were found in both previous to COVID current samples. Multidrug-resistant organisms were subjected to molecular characterization to detect the presence of carbapenem genes. Evaluation data of both pre-and during Coronavirus Disease or COVID-19 were compared. The prevalence of pathogenic (Klebsiella spp., E. coli, and Pseudomonas spp.) and nonpathogenic (Staphylococcus aureus and Bacillus spp.) strains in healthcare setups decreased drastically (Klebsiella spp. from $80 \%$ to $20 \%$, E.coli from $90 \%$ to $10 \%$ and Pseudomonas spp. from $80 \%$ to $20 \%$ ). It is possible only because of the awareness in non-specialists and healthcare workers due to the unforeseen critical situation proving to be a blessing for the future generation.
\end{abstract}

Keywords: Hospital Acquired Infections, Operation Theatres, Intensive Care Units, pathogen, microbiology surveillance, carbapenem resistance

*Correspondence: anuragzaveri@yahoo.com; +91-9429865689

(Received: March 20, 2021; accepted: April 29, 2021)

Citation: Zaveri AD, Zaveri DN, Bhaskaran L. Molecular Characterization of Isolated Multidrug-Resistant Bacteria from Tertiary Care Hospitals of Ahmedabad: A Comparison Study Between Previous to COVID-19 and Current Scenario .J Pure Appl Microbiol. 2021;15(2):797-802. doi: 10.22207/JPAM.15.2.33

(C) The Author(s) 2021. Open Access. This article is distributed under the terms of the Creative Commons Attribution 4.0 International License which permits unrestricted use, sharing, distribution, and reproduction in any medium, provided you give appropriate credit to the original author(s) and the source, provide a link to the Creative Commons license, and indicate if changes were made. 


\section{INTRODUCTION}

Hospital-acquired infections (HAI) are a menace to the healthcare industry and have proven to be life-threatening ${ }^{1}$. Regular microbiological surveillance of sensitive areas provides essential information related to commonly isolated organisms, and the data helps decide healthcare policies ${ }^{1}$. Clues help specialists to predict infection trends, development of resistance, or colonization ${ }^{2}$. COVID-19 has changed many things we perceived differently, especially in healthcare hygiene ${ }^{3}$. Because of the uncertainty forced upon us by the pandemic, healthcare workers were skeptical and forced to follow the regime strictly. Healthcare workers and patients are forced to maintain distance; access to patients is highly restricted, hands are sanitized or disinfected frequently, faces are covered with masks, PPE kits are worn, the Corona Front Line Warriors take utmost care. Amid this chaos, people developed insight about critical aspects of healthcare viz. infection, epidemic, pandemic, contamination, hygiene disinfection, and surface disinfection, etcetera; however, healthcare, per se, has benefited the most from this situation in terms of awareness ${ }^{4}$. According to the report published by $C D C$, there were an estimated 687,000 Hospital Acquired Infections in U.S. acute care hospitals in 2015. About 72,000 hospital patients with HAls died during their hospitalizations ${ }^{5}$.

\section{MATERIALS AND METHODS}

The study does not involve samples of human origin; hence, the requirement that follows the norms of the declaration of Helsinki is not required. During the investigation, no medicine/placebo was prescribed to humans; hence biological vitals, viz. height, sex, weight, Etc., were not measured. The resistance screened was performed against established formulas only.

\section{Sample collection and strain selection}

In this study, surveillance tests from the critically essential wards, e.g., Intensive Care Units (ICUs), Operation Theaters, various objects of ICU's doctors' station, Etc., of three tertiary care hospitals of Ahmedabad were taken and analyzed between the years April 2017 till July 2020. Samples from the critically essential wards were collected bi-monthly, and the same from non-critical wards were collected on a monthly basis. Hospital premises were fumigated using advanced fumigants having a combination of $\mathrm{H}_{2} \mathrm{O}_{2}$ and $\mathrm{AgNO}_{3}$, surfaces of such vital places were cleaned using Sodium Hypochlorite, Phenyl, and alcohol-based disinfectants. According to the CLSI guideline (2018), sepsis was maintained while collecting air samples, andsurface swabs were collected from frequently used surfaces by making virtual marking of $5 \times 5$ square $\mathrm{cm}$. area ${ }^{6}$. Laboratory consumables were procured from Hi-media Laboratories, Mumbai. Swabs were enriched with nutrient broth and were inoculated on Blood agar and MacConkey agar and incubated at $37^{\circ} \mathrm{C}$ for 24 hours in the laboratory ${ }^{6}$. Active air sampling was carried out using air sampler LA002 (Hi-media Laboratories, Mumbai), having the highest sampling volume of 2520 liters of air max and requiring 3.5 minutes to sample 1000 liters of air having a flow rate of 280 liters/min with particle cut off size of $>3 \mu \mathrm{m}^{7}$. Blood agar (BA), MacConkey agar (Mac), Standard plate count agar (SPC), and Sabouraud Dextrose Agar (SDA) were inoculated. Air passing from the air sampler blows on the strip $^{7}$. Colonies, growing because of the presence of microorganisms, were counted(using colony counter) and processed for further identification (using conventional as well as VITEK-2 compact for identification of isolates) and susceptibility testing (CLSI method) $)^{8,9}$.

\section{Antibiotic susceptibility testing}

Antibiotic susceptibility testing was performed using Kirby-Bauer disk diffusion susceptibility test protocol, and according to the clinical breakpoints recommended by the Clinical and Laboratory Standards Institute (CLSI) guideline (2018), the results were interpreted ${ }^{8,9}$. Following discs, procured from $\mathrm{Hi}$-media Laboratories (Mumbai), were used: cefotaxime-clavulanic acid $(30 / 10 \mu \mathrm{g})$, aztreonam $(30 \mu \mathrm{g})$, cefepime $(30 \mu \mathrm{g})$, ceftriaxone $(30 \mu \mathrm{g})$, cefoxitin $(30 \mu \mathrm{g})$, cefotetan $(30 \mu \mathrm{g})$, meropenem $(10 \mu \mathrm{g})$, imipenem $(10 \mu \mathrm{g})$, ertapenem $(10 \mu \mathrm{g})$, cefotaxime $(30 \mu \mathrm{g})$, ceftazidime + clavulanic acid $(30 / 10 \mu \mathrm{g})$, ceftazidime $(30 \mu \mathrm{g})$.

The method suggested by Parul Sinha et al. was used to type $\beta$-lactamase resistance between isolated organisms to derive the resistance pattern of isolate out of extended-spectrum betalactamases (ES $\beta \mathrm{LS})$, AmpC $\beta$-lactamases ( $\mathrm{AmpC} \beta \mathrm{L}$ ) or metallo- $\beta$-lactamases $(\mathrm{M} \beta \mathrm{L})^{10}$. 
Isolates of the Enterobacteriaceae group showing resistance towards two or more groups of antibiotics were included, whereas organisms from the non- Enterobacteriaceae group and highly susceptible isolates of the Enterobacteriaceae group were excluded from the study, according to the definition of $\mathrm{CDC}^{11}$.

\section{Confirmation of Carbapenem Resistance Modified Hodge test}

A solution of $0.5 \mathrm{McF}$ dilution of ATCC $E$. coli 25922 was prepared in $5 \mathrm{ml}$ quantity, which was diluted in 1:10 dilution factor. Lawn streaking on each $\mathrm{MH}$ agar plate was performed using the diluted inoculum, and it was allowed to dry. Meropenem $(10 \mu \mathrm{g})$ susceptibility disc was placed in the center of the plate, and the test organism was streaked on the plate from the edge of the disc to the edge of the plate. Development of clover leaf-type indentation at the intersection of the test organism and ATCC strain within the zone of inhibition of the carbapenem susceptibility disc indicates positive results; results developed otherwise suggest that the testing organism is negative for carbapenem resistance ${ }^{12}$.

Combined disc test (CDT) / ethylene diamine tetraacetic acid test

Sets of two discs were taken, each containing IPM $(10 \mu \mathrm{g}), \mathrm{MEM}(10 \mu \mathrm{g})$ or ETP (10 $\mu \mathrm{g})$, discs were placed on $\mathrm{MH}$ agar plates, preinoculated with a sample of the test isolate (0.5 McF Standard). After the discs were placed onto the agar, $10 \mu \mathrm{l}$ of $0.1 \mathrm{M}$ EDTA solution was added to one of the two carbapenem discs in each set. Plates were incubated at $37^{\circ} \mathrm{C}$ for 16 to 20 hours, and zone diameters were recorded at the end of the incubation period. The differences in the diameter of $\geq 5 \mathrm{~mm}$ between the APBA-free and APBA-containing discs or between the EDTAfree and EDTA-containing discs were considered indicative of Class $A$ and $B$ carbapenemase production, respectively ${ }^{13}$.

Organisms showing positive results in at least one of the two confirmatory tests, Combined Disc Test (CDT) and Modified Hodge Test, were selected, and the remaining were ruled out from the further genetic analysis.

\section{Molecular Characterization of Isolates}

Genomic DNA of the isolates was extracted using column extraction ${ }^{13}$. Polymerase Chain Reaction (PCR) was carried out on 7500 Real-Time (RT)-PCR machine (ThermoFisher Scientific, USA) using primers of TaqMan chemistry (ThermoFisher Scientific, USA) for bla ${ }_{\mathrm{VIM}-2^{\prime}}$ bla $_{\mathrm{KPC}-3}$, bla ${ }_{\mathrm{NDM}-1}$, and bla ${ }_{\text {IMP-11 }}$ carbapenem genes maintaining conditions described by Van der zee et al. Sample DNA taken was 5.0 $\mu$ l, which was mixed with $25.0 \mu$ l of master mix and $2.50 \mu$ l of assay mix topped up by $17.50 \mu$ l of $\mathrm{H} 2 \mathrm{O}$, ultimately making the final reaction volume to $50.0 \mu l$. The RT-PCR reaction was set for single-plex PCR, although primers have shown positive reactions in multiplex conditions too ${ }^{14}$.

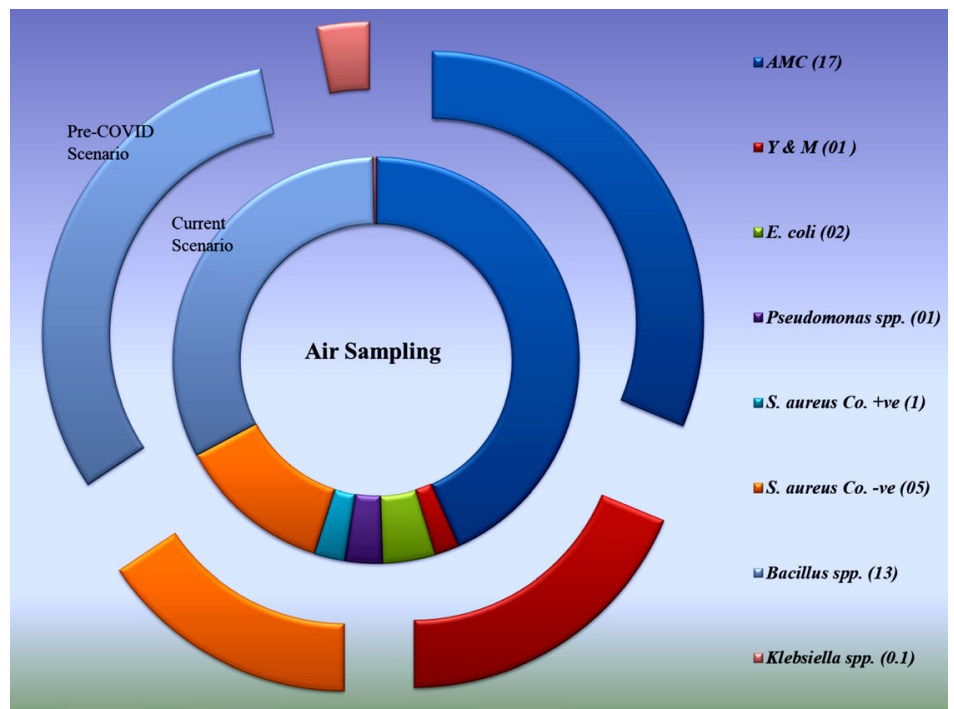

Fig. 1. Comparison of air samplings collected during pre-COVID and current scenario along with the isolation pattern. 


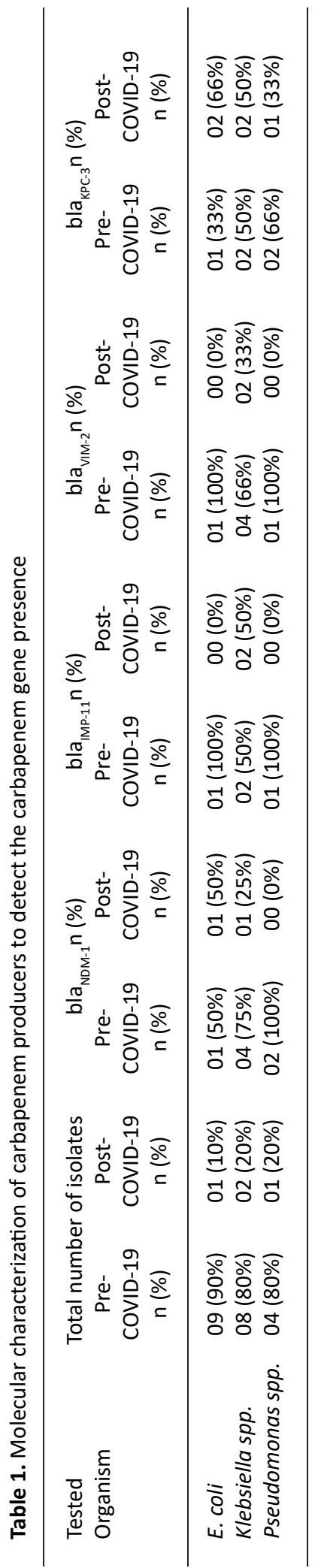

\section{Data Analysis}

Conventional statistical tools were used to analyze the generated data; the critical value used for this testing was that corresponding to a $P$-value of $<0.05$; whereas, the data obtained from RT-PCR were analyzed using 7500-software provided by the manufacturer.

\section{RESULT AND DISCUSSION}

Out of 4400 samples, 2403 surface swabs and 804 air samples were collected before March 2020, and 1055 surface swabs and 138 air samples were collected after March 2020.

Out of total strains screened for antibiotic resistance, 4795 isolates were found nonpathogenic, whereas 484 organisms were found to be resistant to more than one group of antibiotics, multidrug-resistant strains. With the help of confirmatory tests, twenty-five strains of Klebsiella spp., Pseudomonas spp., and E. coliwere selected for molecular characterization to detect the presence of carbapenem-producing genes, figures 1 and 2. Similar findings were observed in the similar research carried out by Bhagirath AY, 2019, although the ratio of multiple drug-resistant organisms was far low as compared to the study.

From table 1, it is evident that the presence of multiple genes was observed in the isolates of Klebsiella spp. and Pseudomonas spp. The most frequently found carbapenem genes were blaNDM-1 and blaKPC-3, which is different from the similar research; gene blaNDM-1 was not one of the most commonly observed genes in their study ${ }^{13}$. The strains with multiple genes were analyzed further for gene expression analysis and by sequencing the whole genome.

In-depth analysis of sensitive areas of healthcare setup is inevitable; guidelines must be followed in maintaining the same since it plays an essential role in restricting hospital-acquired infections (HAIs) ${ }^{15,16,17}$. As per the World Health Organization (WHO) Guidelines to Laboratory Method, OT is considered well-maintained when the bacterial load is found to be lower than $180 / \mathrm{m}^{3}$ of air $^{18,19}$. From the present study, it is evident that though the count was below in the pre-COVID-19 era, it was at far lower levels after following stringent guidelines. Researchers working on antibiotic resistance had similar results that 


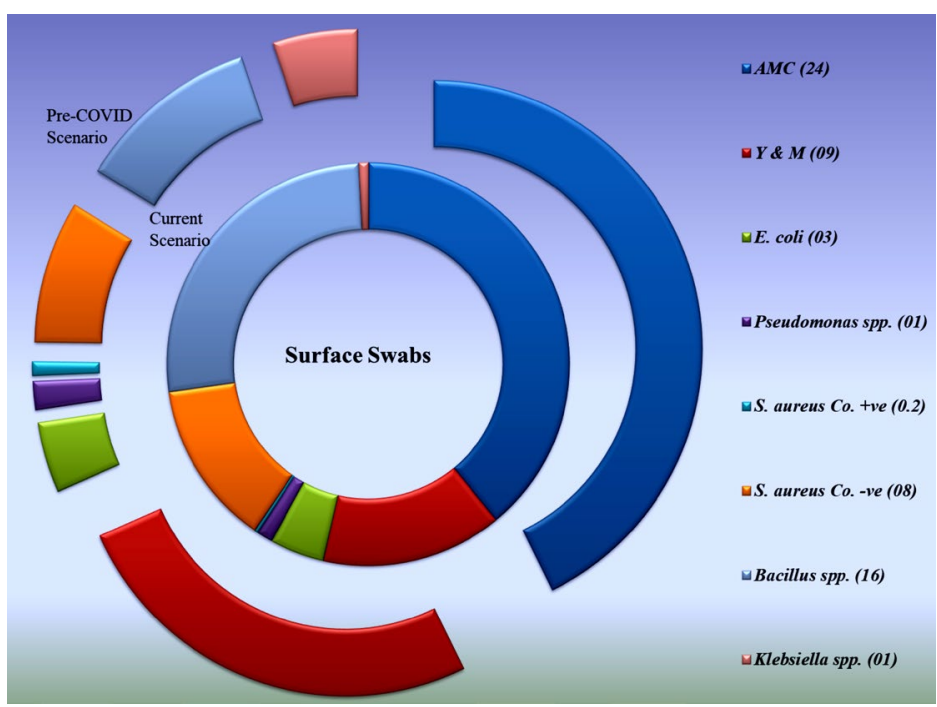

Fig. 2. Pictorial representation of data for the swab samples collected between the period and its isolation pattern

were in line with the study's findings from their five-year extensive research program ${ }^{19}$.

Molecular characterization confirmed the presence of organisms bearing multiple genes isolated from sampling carried out before the COVID-19 pandemic. Through further analysis of whole-genome sequencing, is pending of these isolates, it is evident from the post-COVID-19 data that the overall count of such organisms has decreased drastically, proving to be beneficial to both patients and healthcare setups. The virulence of the strains prevalent and circulating in the hospital would be revealed through the whole genome sequencing and the foreign genome acquired by them from the previously contacted organisms.

The purpose of the study was to highlight that in the current critical situation, when guidelines are stringently followed, the overall presence of organisms was found minimal, and the reason behind it could be frequent cleaning of various surfaces and hands using sanitizers and disinfectants or minimal access to the patients. Maintaining such practices would improve overall healthcare hygiene levels and decrease the hospital-acquired infection ratio, ultimately leading to a better healthcare scenario in the nation. It is in the hands of the healthcare workers to maintain these standards in the future and minimalize the menace of hospital-acquired infections.

\section{CONCLUSION}

It is in human nature to adjust to any situation, so have we during this unprecedented event in the history of humankind; however, with the attained knowledge of every such experience, people evolve. An effort is made by sharing this research to understand that implementation and maintenance of stringent quality control procedures have paid off during the COVID pandemic and should continue to do so, which would provide extraordinary outcomes in the future.All this was possible because of the awareness generated from the current pandemic, and infection control specialists found everyone following the basics. Healthcare workers have followed every single guideline and have fought with the global crisis to the best of their abilities. Due to this, the rate of hospital-acquired infectionshas drastically decreased ${ }^{21}$.

\section{Further research}

Thirty researchers from India are selected to submit their isolates for Whole Genome Sequencing under the Bill and Melinda Gates Foundation project, and a few of the organisms isolated during this study have been sent to KIMS hospital Bangalore, India. The data received from the sequencing will be stored in NHS, the UK, for further analysis. 


\section{ACKNOWLEDGMENTS}

We thank Biocare Research (I) Pvt. Ltd. and its entire staff members for their continuous support in carrying out this fundamental research.

\section{CONFLICT OF INTEREST}

The authors declare that there is no conflict of interest.

\section{AUTHORS' CONTRIBUTION}

All authors listed have made a substantial, direct and intellectual contribution to the work, and approved it for publication.

\section{FUNDING}

None.

\section{DATA AVAILABILITY}

All datasets generated or analyzed during this study are included in the manuscript.

\section{ETHICS STATEMENT}

Not applicable.

\section{REFERENCES}

1. Ducel G, Fabry J, Nicolle L. Prevention of hospitalacquired infections. 2nd edition Malta, Switzerland 2002.

2. Zerr DM, Garrison MM, Allpress AL, Heath J, Christakis DA. Infection control policies and hospital-associated infections among surgical patients: variability and associations in a multi-center-pediatric setting. Pediatrics. 2005;115(4):e387-e392. doi: 10.1542/ peds.2004-2014

3. American hospital association [internet] Chicago: American Hospital Association TM; (C) 2020. https:// www.aha.org/system/files/media/file/2020/05/ahacovid19-financial-impact-0520-FINAL.pdf

4. Desai SN,Kikani KM, Mehta SJ. Microbiological Surveillance of Operation Theaters \& Intensive Care Units of Teaching Hospital in Surendranagar, Gujarat. GMJ. 2012:67(2);95-97.

5. Healthcare-associated Infections, Centers for Disease Control and Prevention. Accessed April 04, 2021. https://www.cdc.gov/hai/data/portal/index.html

6. CLSI. Performance Standards for Antimicrobial Susceptibility Testing. 28th ed. CLSI supplement M100. Wayne, PA: Clinical and Laboratory Standards Institute; 2018. ISBN: 156238838X; https://clsi.org/standards/ products/microbiology/documents/m100

7. Clinical and Laboratory Standards Institute (CLSI). M100 performance standard for susceptibility testing, 28th edition PA, USA, 2018.

8. Jan Hudzicki. Kirby-Bauer disk diffusion susceptibility test protocol, American Society for Microbiology, 2009.
9. Sinha P, Goyal P, Sharma R, Vyas A, Maheshwari RK. Evaluation of a 12 Disc Test for Phenotypic Detection of $\beta$ - lactamases Resistance in Gram-Negative Bacilli. Int.J.Curr.Microbiol.App.Sci. 2016;5(6):105-114. doi: 10.20546/ijcmas.2016.506.013

10. Kelkar U, Kelkar S, Bal AM, Kulkarni S, Kulkarni S. Microbiological evaluation of various parameters in ophthalmic operating rooms. The need to establish guidelines. Indian J Ophthalmol. 2003;51:171-176.

11. Ramana KV, Rao R, Sharada ChV, Kareem M, Reddy LR, Ratna Mani M. Modified Hodge test: A useful and the low-cost phenotypic method for detection of carbapenemase producers in Enterobacteriaceae members. J Nat Sci Biol Med. 2013;4(2):346-348. doi:10.4103/0976-9668.117009

12. Pournaras $\mathrm{S}$, Zarkotou $\mathrm{O}$, Poulou A, et al. A combined disk test for direct differentiation of carbapenemaseproducing Enterobacteriaceae in surveillance rectal swabs. J Clin Microbiol. 2013;51(9):2986-2990. doi: 10.1128/JCM.00901-13

13. van der Zee A, Roorda L, Bosman G, et al. Multicenter evaluation of Real-time multiplex PCR for detection of Carbapenemase genes OXA-48, VIM, IMP, NDM, and KPC. BMC Infectious Diseases, 2014;14,27. doi: 10.1186/1471-2334-14-27

14. Himedialabs.com [Internet]. Mumbai: Himedia Laboratories, (c) Himedia Laboratories. http:// himediadownloads.com/MSDS/LA002.pdf

15. Lalitha MK, Manoharan A, Pai R, Thomas K. Determination of penicillin resistance in Streptococcus pneumoniae and use of co-trimoxazole in treatment of pneumococcal pneumoniae. J Clin Microbiol. 1999;37(8):2743-2744.

16. Thermofisher.com [Internet]. Mumbai: Thermo Fisher Scientific Inc.; c 2016. https://www.thermofisher. com/content/dam/LifeTech/Documents/PDFs/ COL11485_4_Tq_Mn_Assy_Prmo_Flyr_Infct_Diseas_ VS.pdf

17. Bhagirath AY, Li Y, Patidar R, et al. Two Component Regulatory Systems and Antibiotic Resistance in GramNegative Pathogens. Int J Mol Sci. 2019;20(7):1781. doi:10.3390/ijms20071781

18. Singh K, Dar FA, Kishor K. Bacterial contamination in operating theatres of district hospital Budgam in Kashmir division. Innov J Med Health Sci. 2013; (3):6263.

19. Najotra DK, Malhotra AS, Slathia P, Raina S, Dhar A. Microbiological Surveillance of Operation Theatres: Five Year Retrospective Analysis from a Tertiary Care Hospital in North India. Int J Appl Basic Med Res. 2017;7(3):165-168. doi: 10.4103/ijabmr. IJABMR_281_16

20. Najotra DK, Kakru DK. Bacteriology and antibiogram of skin and soft tissue infections from a tertiary care hospital. Indian J Med Spec 2012;(3):26-30. doi: 10.7713/ijms.2012.0007

21. Jabarpour $M$, Dehghan $M$, Afsharipour $G$, et al., The Impact of COVID-19 Outbreak on Nosocomial Infection Rate: A Case of Iran. Canadian Journal of Infectious Diseases and Medical Microbiology. 2021;2021,6650920. doi: 10.1155/2021/6650920 